CLINICAL STUDY

\title{
Adrenal endothelin-1 levels are not associated with aldosterone secretion in primary aldosteronism
}

\author{
F Morello, D Schiavone, G Mengozzi ${ }^{1}$, C Bertello, C C Liew ${ }^{2}$, D Bisbocci, P Mulatero and F Veglio \\ Fourth Division of Internal Medicine and Hypertension Unit, San Giovanni Battista Hospital of Torino, University of Torino, Via Genova 3,10126 Torino, \\ Italy, ${ }^{1}$ Clinical Chemistry Laboratory, San Giovanni Battista Hospital of Torino, Torino, Italy and ${ }^{2}$ GeneNews Ltd, Richmond Hill, Ontario, Canada \\ (Correspondence should be addressed to F Morello; Email: fulvio.morello@unito.it)
}

\begin{abstract}
Background: Endothelin-1 (ET-1) may function as an aldosterone secretagogue and, in turn, aldosterone can upregulate ET-1 expression. Hence, the existence of a feedforward loop involving ETs and aldosterone has been speculated in primary aldosteronism (PA). In the present study, we sought to examine ET-1 secretion from the adrenal glands in patients with PA.

Design: We determined ET-1 levels in blood samples obtained during adrenal venous sampling of patients affected by PA $(n=17)$. Furthermore, we examined the mRNA expression of the ET system in tissue samples from aldosterone-producing adenomas (APAs, $n=9$ ) and control normal adrenals $(n=3)$.

Methods: Blood ET-1 levels were determined by RIA. Tissue mRNA expression of the ET system was assayed with Affymetrix microarrays.

Results: ET-1 levels did not differ between inferior vena cava and adrenal vein blood in both bilateral adrenal hyperplasia and APA patients. Moreover, cortisol-normalized ET-1 levels did not show lateralized adrenal ET-1 secretion in APAs. Through gene expression profiling with microarray performed in a distinct set of APA individuals $(n=9)$, we confirmed the adrenal expression of a complete ET system, but we did not detect a significant upregulation of ET components within the APA tissue compared with normal adrenals.

Conclusions: The present data argue against the hypothesis of increased ET-1 secretion from APAs and do not support a general role for adrenal ET-1 in the vascular pathophysiology of PA.
\end{abstract}

European Journal of Endocrinology $160453-458$

\section{Introduction}

Endothelins (ET-1, ET-2, and ET-3) are potent vasoactive peptides with biological activity in several cardiovascular diseases, including pulmonary hypertension $(1,2)$, systemic arterial hypertension (3), and heart failure (4). Several lines of evidence have suggested that there is a functional link between ETs and aldosterone. First, ETs (in particular ET-1 and ET-2) have been shown to act via ET(A) and ET(B) receptors as aldosterone secretagogues in vitro and in vivo (5-11). Secondly, ETs may promote activation and proliferation of adrenal cells (12). Recent studies have also shown that aldosterone can, in turn, upregulate ET-1 expression (13-15). Since normal adrenal tissue and adrenal adenomas express components of the ET system (16-18), a positive feedback loop between ETs and aldosterone may be hypothesized. Moreover, any ET spillover from the adrenal gland may have pathophysiological and diagnostic implications.

Primary aldosteronism (PA) is the most common secondary form of hypertension and accounts for $5-10 \%$ of all hypertensive patients (19). PA is characterized by inappropriate aldosterone secretion, mostly from an aldosterone-producing adrenal adenoma (APA) or from idiopathic bilateral adrenal hyperplasia (BAH) (20). Our group and others have shown in previous studies that ET-1 levels in peripheral blood are not elevated in PA patients when compared with matched essential hypertensive patients $(21,22)$. However, peripheral blood ET-1 levels may not reflect adrenal blood levels. In order to assay the adrenal activation of the ET system in PA directly, we have measured ET-1 in samples obtained from adrenal venous blood and we have compared the expression levels of ETs, endothelin-converting enzymes (ECE-1, ECE-2), and ET receptors ET(A) and ET(B) in tissue samples from APAs and control normal adrenal tissue.

\section{Materials and methods}

\section{Patients}

The study protocol and procedures were approved by our institution's responsible committee and all patients 
provided written informed consent. The study involved two different groups of patients with PA (outlined in Table 1). PA and its subtypes, APA and BAH, were diagnosed according to widely accepted diagnostic criteria $(20,23)$. Briefly, patients were screened using the aldosterone plasma aldosterone concentration (PAC)/plasma renin activity (PRA) ratio (ARR). The ARR cut-off level considered to be 'positive' was (40 ng/dl per $\mathrm{ng} \times \mathrm{ml}^{-1} \mathrm{~h}^{-1} ; 4000 \mathrm{pmol} / \mathrm{l}$ per $\mathrm{ng} \times$ $\mathrm{l}^{-1} \mathrm{~s}^{-1}$ ) together with an aldosterone level of $>15 \mathrm{ng} / \mathrm{dl}$ (416 pmol/l). Blood samples were obtained in the sitting position between 0800 and $1000 \mathrm{~h}$. Patients discontinued all anti-hypertensive drugs at least 3 weeks before PAC and PRA measurements were taken. Diuretics were stopped at least 6 weeks before and spironolactone stopped at least 8 weeks before testing. Patients were advised to maintain a diet of normal and constant sodium intake $(120 \mathrm{mmol}$ sodium and $60 \mathrm{mmol}$ potassium per day). Patients who strictly required drug therapy were permitted to take an $\alpha$-blocker (doxazosin) and/or a calcium channel blocker (verapamil or amlodipine). This therapy was maintained throughout screening to final diagnosis.

The confirmatory test was an i.v. saline load (2 l of $0.9 \% \mathrm{NaCl}$ infused over $4 \mathrm{~h}$ ), which was considered positive if post-test aldosterone levels were $>5 \mathrm{ng} / \mathrm{dl}$ (138.7 pmol/l) (24). Fine-cut CT scanning $(2.5 \mathrm{~mm})$ of the adrenal glands was performed in all patients with a positive confirmatory test. Adrenal vein cannulation was considered successful if the adrenal vein/inferior vena cava (IVC) cortisol gradient was at least 2 (catheterization ratio); lateralization was considered when the aldosterone/cortisol ratio $(\mathrm{A} / \mathrm{C})$ from one adrenal was at least four times the ratio from the other adrenal gland (lateralization ratio, (LR)) or if it was three times the contralateral together with an $\mathrm{A} / \mathrm{C}$ in the contralateral lower than the $\mathrm{A} / \mathrm{C}$ in the peripheral vein (contralateral ratio). All patients underwent adrenal vein sampling (AVS) without ACTH stimulation. The presence of an adenoma was confirmed after adrenalectomy. Finally, all patients with PA were screened for glucocorticoid-remediable

Table 1 Clinical and anthropometric parameters of enrolled individuals (adrenal blood endothelin-1 (ET-1) study and adrenal microarray study).

\begin{tabular}{lcc}
\hline & $\begin{array}{c}\text { Adrenal blood } \\
\text { ET-1 study }\end{array}$ & $\begin{array}{c}\text { ET system gene } \\
\text { expression } \\
\text { study }\end{array}$ \\
\hline$N$ & 17 & 9 \\
$\mathrm{M} / \mathrm{F}$ & $13 / 4$ & $5 / 4$ \\
Age (years) & $54 \pm 7$ & $54 \pm 8$ \\
$\mathrm{BMl}\left(\mathrm{kg} / \mathrm{m}^{2}\right)$ & $28.4 \pm 4.6$ & $26.5 \pm 2.9$ \\
Creatinine $(\mathrm{mg} / \mathrm{dl})$ & $1.0 \pm 0.2$ & $0.9 \pm 0.3$ \\
Potassium (mEq/l) & $3.6 \pm 0.7$ & $3.1 \pm 0.9$ \\
PRA (ng Ang l/ml per hour) & $0.3 \pm 0.3$ & $0.2 \pm 0.1$ \\
Aldosterone (pg/ml) & $419 \pm 228$ & $530 \pm 279$ \\
\hline
\end{tabular}

aldosteronism using a long PCR technique (25). PRA, cortisol, and aldosterone were measured as described previously (25).

A final diagnosis of APA was considered 'proven' only when all of the following conditions were satisfied: i) histological demonstration of adenoma, ii) normalization of hypokalemia if present, iii) cure (i.e., normal blood pressure levels without treatment) or improvement (i.e., normal blood pressure achieved with a reduced number of drugs compared with before adrenalectomy) of hypertension, and iv) normalization of ARR and suppressibility of aldosterone levels below $5 \mathrm{ng} / \mathrm{dl}$ under saline load. All patients with a diagnosis of APA underwent adrenalectomy and had the above conditions satisfied. In particular, all patients had an ARR $<20$ and a PRA $>1$ after adrenalectomy.

To determine the ET-1 levels in adrenal vein blood, 17 adult patients with confirmed PA undergoing AVS were included. Based on AVS, seven were diagnosed with APA and ten with BAH. For our gene expression assays, we obtained normal adrenal tissue samples $(n=3)$ from patients undergoing monolateral nephrectomy and consensus ipsilateral adrenectomy for localized (T1-2, NO, MO) renal carcinoma and who were otherwise healthy and normotensive. APA tissue samples $(n=9)$ were obtained from patients undergoing therapeutic monolateral adrenectomy. All tissue samples were collected at the time of adrenectomy, briefly washed with cold saline, immediately submerged in RNAlater solution (which preserves RNA integrity until extraction), and stored at $-80{ }^{\circ} \mathrm{C}$ until further use.

\section{Endothelin-1 measurement}

Only samples obtained from successful and diagnostic adrenal vein cannulation were used, as demonstrated by the concomitant measurement of cortisol levels $(20,23)$. Adrenal vein blood samples were collected in chilled EDTA-treated test tubes during routine AVS. Plasma was separated by centrifugation, added with aprotinin (0.6 TIU/ml blood), immediately snap frozen, and stored at $-80{ }^{\circ} \mathrm{C}$ until further use. Plasma ET-1 was measured by RIA (DRG Inc., Mountainside, NJ, USA) after extraction with SPEC C18 cartridges, according to the manufacturer's protocol. Assays were run in duplicate, and values were expressed in picograms per milliliter $(\mathrm{pg} / \mathrm{ml})$. The intra- and interassay coefficients of variation were respectively 4 and $9 \%$. To account for cannulation variability, raw ET-1 concentrations in adrenal blood samples were normalized by local cortisol concentrations (cortisol-normalized ET-1, calculated as ET-1 concentration divided by cortisol concentration in the same sample, pg ET-1/ $\mu$ g cortisol). Finally, an ET-1 LR was determined (ET1-LR, cortisol-normalized ET-1 on side 1 divided by cortisol-normalized ET-1 on side 2). 


\section{RNA extraction and microarray analysis}

After adrenectomy, the adrenal glands were first carefully dissected, removing the surrounding connective tissues and separating the adrenal cortex from the medulla. For both APA and control samples, RNA was extracted from $100 \mathrm{mg}$ of adrenal tissue. In the case of APAs, the tissue samples for RNA extraction were obtained within the adenoma, discarding the capsule. For control adrenal glands, the adrenal cortex was cut on its transversal axis and the tissue sample for RNA extraction was obtained from the outer part of the cortex. In preliminary studies, we verified on histological sections that this area spanned across the zona glomerulosa and part of the fasciculata zone of the adrenal cortex. Total RNA was extracted with TRIzol reagent and precipitated in isopropanol, following standard protocols (26). All RNA samples were assayed for purity and quality, using an Agilent Bioanalyzer, according to the manufacturer's instructions. For gene expression profiling studies, we chose the oligonucleotide Affymetrix GeneChip Human Genome U133 Plus 2.0 Array, which allows analysis of more than 47000 transcripts. We performed cRNA synthesis and labeling, hybridization, and scanning, following the manufacturer's protocols as previously described (27).

CEL files were analyzed using dChip 2006 Software (9). Briefly, the data underwent invariant set normalization in order to adjust for differences in overall array brightness. Expression levels of probe sets were then computed using the model-based expression indexes. Next, we queried for further analysis all the probe sets $(n=20)$ exploring the gene transcripts of the endothelin system (ET-1, ET-2, ET-3, ECE-1, ECE-2, ET(A), and ET(B)). Only probe sets producing a presence (P) call in $>50 \%$ of normal adrenal samples and in $>50 \%$ of APA samples were considered. For each filtered probe set, a fold change value was determined as the ratio of average expression level in the APA and in the normal adrenal group.

Microarray results were validated using quantitative real-time PCR (qRT-PCR). qRT-PCR was performed in a two-step fashion. RT was performed in the presence of $50-100 \mathrm{ng} / \mu \mathrm{l}$ total $\mathrm{RNA}, 10 \mathrm{ng} / \mu \mathrm{l}$ random primers, $500 \mathrm{nM}$ dNTPs, $0.1 \mathrm{M}$ dithiothreitol, and $10 \mathrm{U} / \mu \mathrm{l}$ SuperScript II Reverse Transcriptase (Invitrogen) in first-strand buffer. Quantitative PCR was subsequently performed using TaqMan chemistry (ABI) on an Applied Biosystems ABI 7500 instrument, following the standard protocols. Primers and probes were predesigned assays by ABI. Gene expression levels were analyzed using the $2^{-\Delta \Delta C_{\mathrm{t}}}$ relative quantification system, using $\beta$-actin as the endogenous control gene.

\section{Statistical analysis}

Values are expressed throughout as average \pm s.E.M. Differences between groups were analyzed by one-way
ANOVA or Student's $t$-test, using $P<0.05$ as statistically significant.

\section{Results}

\section{ET-1 levels in AVS samples}

We measured ET-1 levels in blood samples obtained from the right and left adrenal veins and from the IVC during AVS performed in 17 patients with PA, as described above. The clinical and anthropometric parameters of patients are reported in Table 1.

Overall, average ET-1 levels in the adrenal veins $(n=17)$ were similar to ET- 1 levels in the IVC $(5.2 \pm 0.5$ vs $4.3 \pm 0.5 \mathrm{pg} / \mathrm{ml}, P=0.27)$. Also, in APA patients $(n=7)$, no difference was observed in the ET-1 levels in the adrenal veins when compared with those in the IVC $(5.0 \pm 1.2$ vs $4.1 \pm 0.9 \mathrm{pg} / \mathrm{ml}, P=0.54)$. Furthermore, raw ET-1 levels in adrenal vein blood were similar ipsilaterally and contralaterally to the APA $(6.3 \pm 2.2$ vs $3.7 \pm 0.7 \mathrm{pg} / \mathrm{ml}, P=0.27$ ). Even after normalization for local cortisol levels (to account for sampling variability related to adrenal vein cannulation), normalized adrenal blood ET-1 levels did not differ ipsilaterally and contralaterally to the APA $(4.3 \pm 2.5$ vs $7.2 \pm$ $3.4 \mathrm{pg} \mathrm{ET}-1 / \mu \mathrm{g}$ cortisol), a finding that rules out clearcut ET-1 lateralization in APAs (Fig. 1A). Average ET1LR in APAs was $1.5 \pm 0.7$ (range 0.1-5.3), with only one APA showing lateralized ET-1 secretion (ET1-LR 5.3) and all others presenting ET1-LR lower than 1 $(n=3)$ or between 0 and $2(n=3)$.

In BAH patients $(n=10)$, ET- 1 levels were similar in adrenal veins and IVC (right adrenal vein $5.6 \pm$ $0.4 \mathrm{pg} / \mathrm{ml}$, left adrenal vein $5.2 \pm 0.5 \mathrm{pg} / \mathrm{ml}$, IVC $4.5 \pm$ $0.6 \mathrm{pg} / \mathrm{ml}, P=0.28)$. No difference was detected between right and left cortisol-normalized adrenal blood ET-1 levels (Fig. 1B). ET1-LRs ranged between 0.1 and 17.8 , with most individuals $(n=7)$ presenting an ET1-LR between 0.5 and 2.0.

\section{Gene expression of the ET system in adrenal samples}

To validate these results using a different technological platform and a different set of subjects, we examined the gene expression fingerprint of the ET system in adrenal tissue samples obtained from patients with APA $(n=9)$ and subjects with normal adrenals $(n=3)$. Microarray data analysis was performed as described in 'Materials and methods' section. The clinical and anthropometric parameters of patients and controls are reported in Table 1.

Like other investigators $(17,18)$, we detected a significant expression of ET-1, ECE-1, ECE-2, ET(A), and $\mathrm{ET}(\mathrm{B})$ in all adrenal samples. Based on signal/noise criteria, however, the signal we obtained from probes exploring ET-2 and ET-3 was non-significant, and we 

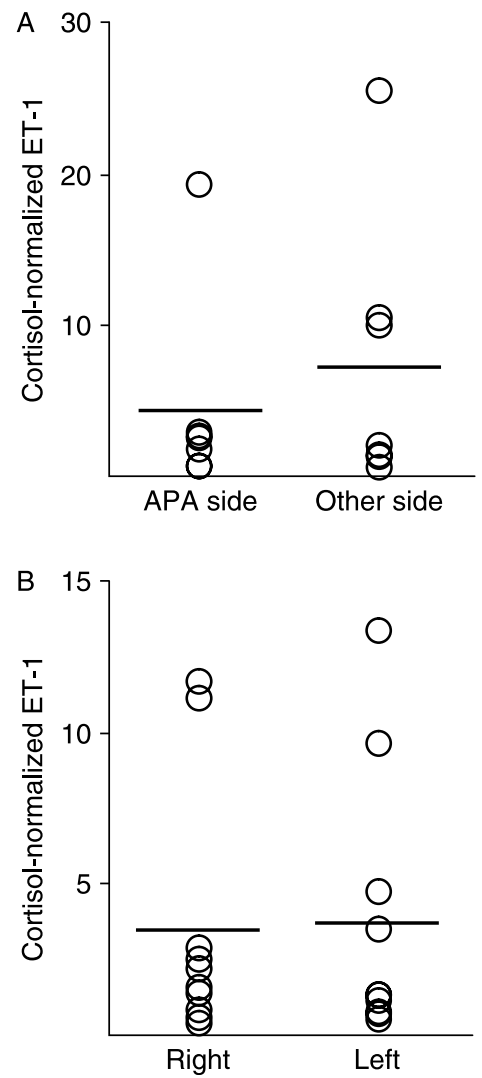

Figure 1 Scatter plots of cortisol-normalized adrenal blood ET-1 levels in enrolled individuals. (A) Cortisol-normalized ET-1 levels (see Materials and methods section) in adrenal blood samples of APA patients $(n=7)$, pg ET-1/ $\mu \mathrm{g}$ cortisol. APA side, adrenal vein ipsilateral to the APA; other side, adrenal vein contralateral to the APA. (B) Cortisol-normalized ET-1 levels in adrenal blood samples

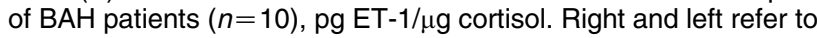
the side of the adrenal vein.

considered ET-2 and ET-3 to be absent in the study samples. The average normalized probe intensities (which represent expression levels and allow for interarray comparison) of ET system mRNAs are shown in Fig. 2. No significant difference was observed between ET-1 mRNA levels in APAs and in normal adrenal samples (fold change: $-1.06, P=0.84$ ). Similarly, ECE-1 (fold change: - 1.01), ECE-2 (fold change: -1.31 ), ET(A) (fold change: -1.02 ), and ET(B) (fold change: - 1.04) were all similarly expressed in APA samples when compared with normal adrenals $(P>0.05)$. Microarray findings were further confirmed by quantitative real-time PCR (data not shown).

\section{Discussion}

ETs are peptides involved in cardiovascular physiology and disease. ETs can also stimulate aldosterone secretion from adrenal cells (5-11), and aldosterone may, in turn, upregulate ET-1 expression (13-15).

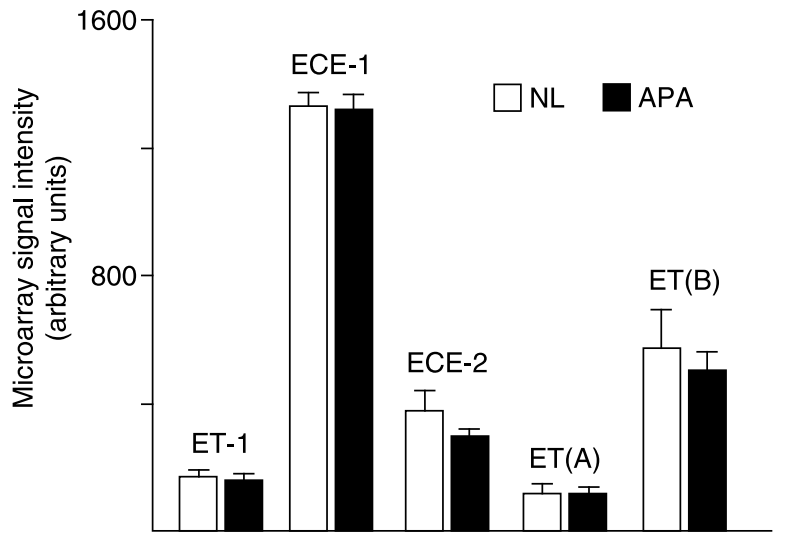

Figure 2 mRNA expression of ET-1, ECE-1, ECE-2, ET(A), and $\mathrm{ET}(\mathrm{B})$ in APA $(n=9)$ and normal adrenal $(n=3)$ tissue samples. Expression is based on the microarray signal intensity of corresponding probes.

Several components of the ET system (ET-1, ECE-1, $\mathrm{ET}(\mathrm{A})$, and $\mathrm{ET}(\mathrm{B}))$ have been detected in normal adrenals and in APAs (16-18), a prototypical cause of PA. Overall, these findings have led investigators to speculate that a feedforward loop of ETs and aldosterone may be involved in the pathogenesis of PA. Although ET-1 levels in the peripheral blood PA patients are similar to the levels in controls $(21,22)$, peripheral blood levels may not be informative about local adrenal ET secretion. To address this issue, we have evaluated ET-1 levels in blood samples obtained from the adrenal veins of patients with PA. These vessels collect venous blood arising from the adrenal glands. Their cannulation and sampling for the measurement of local aldosterone and cortisol levels is the gold standard in the diagnosis workup of PA (23). In this study, we did not detect a significant difference in the ET-1 levels between adrenal vein and IVC samples. Also, in BAH, which is characterized by excessive bilateral aldosterone secretion, the levels of ET-1 in adrenal veins and IVC were similar. ET-1 levels were also similar in the adrenal vein samples both ipsilaterally and contralaterally to APAs.

In addition to the above studies, we quantitatively assessed mRNA expression of the various ET system components in a group of APA samples when compared with normal control adrenals. Our microarray assay confirmed the expression of ET-1, ECE-1, and both ET receptor in adrenal tissues (normal and adenomatous), as reported in the previous studies (16-18). ET-2 and ET-3 mRNA was undetectable. We also found significant levels of adrenal ECE-2 in normal adrenals and APA. Overall, the ET system appears to be fully expressed in the adrenal tissue. However, we could not detect significant differences in ET-1, ECEs, and ET receptor expression levels in APA samples when compared with normal adrenal controls. These last data, obtained in a 
different set of patients and confirmed by qRT-PCR, corroborate our ET-1 immunoassay findings.

Previous studies have reported significant heterogeneity in the gene expression fingerprints and overall phenotypes of APAs $(28,29)$. We did detect significantly higher levels of ET-1 in one subject ipsilaterally to the APA. We also found that in one of the APA tissue samples, ET-1 mRNA was 1.64-fold upregulated when compared with normal adrenal tissue samples. Hence, we cannot rule out that some APAs may have ET-1 overproduction and secretion in the bloodstream. Further studies of ET expression and adrenal blood levels in a larger number of subjects will be necessary to address the present issue.

Overall, our data undermine the hypothesis that adrenal gland ET-1 secretion is enhanced in PA and argue against a general role for adrenal ETs in the vascular pathophysiology of PA. However, a number of questions remain open. First, our data do not rule out a paracrine role for the ET system in the adrenal biology of PA. In fact, it is possible that a vascular-adrenal cell feedforward loop between ET-1 and aldosterone may be locally active without affecting ET-1 levels in the collecting venous vessels. Furthermore, a longer feedforward loop between aldosterone and ET-1 could be active in other tissues. In fact, it is possible that in PA the high levels of circulating aldosterone may lead to a local overexpression of ET-1 in vessels and tissues, hence contributing to the vascular pathophysiology and target organ damage of PA. Finally, although circulating ET-1 levels of PA patients are similar to those of control hypertensive individuals, it is also conceivable that aldosterone and ET-1 may work in biological synergy, leading to increased ET-1 and/or aldosterone actions in PA.

\section{Declaration of interest}

The authors declare no conflicts of interest that could be perceived as prejudicing the impartiality of the research.

\section{Funding}

The present study was supported by grants from MUR. (ex 60\%), Regione Piemonte (Ricerca Finalizzata 2006), University of Torino, and Compagnia di San Paolo di Torino.

\section{Acknowledgements}

The authors kindly acknowledge the patients participating in this study for their help and interest.

\section{References}

1 Giaid A, Yanagisawa M, Langleben D, Michel RP, Levy R, Shennib H, Kimura S, Masaki T, Duguid WP \& Stewart DJ. Expression of endothelin-1 in the lungs of patients with pulmonary hypertension. New England Journal of Medicine $19933281732-$ 1739 .
2 Rubin LJ, Badesch DB, Barst RJ, Galie N, Black CM, Keogh A, Pulido T, Frost A, Roux S, Leconte I, Landzberg M, Simonneau G \& the Bosentan Randomized Trial of Endothelin Antagonist Therapy Study G. Bosentan therapy for pulmonary arterial hypertension. New England Journal of Medicine 2002346 896-903.

3 Krum H, Viskoper RJ, Lacourciere Y, Budde M, Charlon V \& The Bosentan Hypertension I. The effect of an endothelin-receptor antagonist, bosentan, on blood pressure in patients with essential hypertension. New England Journal of Medicine $1998 \mathbf{3 3 8}$ 784-791.

4 Kiowski W, Sutsch G, Hunziker P, Muller P, Kim J, Oechslin E, Schmitt R, Jones R \& Bertel O. Evidence for endothelin-1-mediated vasoconstriction in severe chronic heart failure. Lancet $19953 \mathbf{3 4}$ $732-736$.

5 Cozza EN, Gomez-Sanchez CE, Foecking MF \& Chiou S. Endothelin binding to cultured calf adrenal zona glomerulosa cells and stimulation of aldosterone secretion. Journal of Clinical Investigation $1989841032-1035$.

6 Morishita R, Higaki J \& Ogihara T. Endothelin stimulates aldosterone biosynthesis by dispersed rabbit adreno-capsular cells. Biochemical and Biophysical Research Communications 1989 160 628-632.

7 Cozza EN, Chiou S \& Gomez-Sanchez CE. Endothelin-1 potentiation of angiotensin II stimulation of aldosterone production. American Journal of Physiology 1992262 R85-R89.

8 Hinson JP, Kapas S, Teja R \& Vinson GP. Effect of the endothelins on aldosterone secretion by rat zona glomerulosa cells in vitro. Journal of Steroid Biochemistry and Molecular Biology $1991 \mathbf{4 0}$ 437-439.

9 Delarue C, Delton I, Fiorini F, Homo-Delarche F, Fasolo A, Braquet P \& Vaudry H. Endothelin stimulates steroid secretion by frog adrenal gland in vitro: evidence for the involvement of prostaglandins and extracellular calcium in the mechanism of actin of endothelin. Endocrinology 1990127 2001-2008.

10 Rosolowsky LJ \& Campbell WB. Endothelin enhances adrenocorticotropin-stimulated aldosterone release from cultured bovine adrenal cells. Endocrinology 1990126 1860-1866.

11 Zeng ZP, Naruse M, Guan BJ, Naruse K, Sun ML, Zang MF, Demura H \& Shi YF. Endothelin stimulates aldosterone secretion in vitro from normal adrenocortical tissue, but not adenoma tissue, in primary aldosteronism. Journal of Clinical Endocrinology and Metabolism 1992 74 874-878.

12 Delarue C, Conlon JM, Remy-Jouet I, Fournier A \& Vaudry H. Endothelins as local activators of adrenocortical cells. Journal of Molecular Endocrinology 200432 1-7.

13 Wong S, Brennan FE, Young MJ, Fuller PJ \& Cole TJ. A direct effect of aldosterone on endothelin-1 gene expression in vivo. Endocrinology $2007 \mathbf{1 4 8} 1511-1517$.

14 Wolf SC, Schultze M, Risler T, Rieg T, Lang F, Schulze-Osthoff K \& Brehm BR. Stimulation of serum- and glucocorticoid-regulated kinase-1 gene expression by endothelin-1. Biochemical Pharmacology 2006711175.

15 Gumz ML, Popp MP, Wingo CS \& Cain BD. Early transcriptional effects of aldosterone in a mouse inner medullary collecting duct cell line. American Journal of Physiology. Renal Physiology 2003 285 F664-F673.

16 Rossi G, Albertin G, Belloni A, Zanin L, Biasolo MA, PrayerGaletti T, Bader M, Nussdorfer GG, Palu G \& Pessina AC. Gene expression, localization, and characterization of endothelin A and $\mathrm{B}$ receptors in the human adrenal cortex. Journal of Clinical Investigation $1994941226-1234$.

17 Egidy G, Baviera E, Ciuffo G, Corvol P \& Pinet F. Localization of the endothelin system in aldosterone-producing adenomas. Hypertension 200138 1137-1142.

18 Rossi G, Belloni AS, Albertin G, Zanin L, Biasolo MA, Nussdorfer GG, Palu G \& Pessina AC. Endothelin-1 and its receptors $\mathrm{A}$ and $\mathrm{B}$ in human aldosterone-producing adenomas. Hypertension $1995 \mathbf{2 5} 842-847$. 
19 Mulatero P, Dluhy RG, Giacchetti G, Boscaro M, Veglio F \& Stewart PM. Diagnosis of primary aldosteronism: from screening to subtype differentiation. Trends in Endocrinology and Metabolism 200516 114-119.

20 Mulatero P, Stowasser M, Loh K-C, Fardella CE, Gordon RD, Mosso L, Gomez-Sanchez CE, Veglio F \& Young WF Jr. Increased diagnosis of primary aldosteronism, including surgically correctable forms, in centers from five continents. Journal of Clinical Endocrinology and Metabolism 200489 1045-1050.

21 Veglio F, Melchio R, Rabbia F \& Chiandussi L. Plasma immunoreactive endothelin-1 in primary hyperaldosteronism. American Journal of Hypertension 19947 559-561.

22 Letizia C, De Toma G, Cerci S, Scuro L, De Ciocchis A, D’Ambrosio C, Massa R, Cavallaro A \& Scavo D. Plasma endothelin-1 levels in patients with aldosterone-producing adenoma and pheochromocytoma. Clinical and Experimental Hypertension $199618921-931$.

23 Mulatero P, Bertello C, Rossato D, Mengozzi G, Milan A, Garrone C, Giraudo G, Passarino G, Garabello D, Verhovez A, Rabbia F \& Veglio F. Roles of clinical criteria, CT scan and adrenal vein sampling in differential diagnosis of primary aldosteronism subtypes. Journal of Clinical Endocrinology and Metabolism 2008 93 1366-1371.

24 Mulatero P, Milan A, Fallo F, Regolisti G, Pizzolo F, Fardella C, Mosso L, Marafetti L, Veglio F \& Maccario M. Comparison of confirmatory tests for the diagnosis of primary aldosteronism. Journal of Clinical Endocrinology and Metabolism 2006912618 2623.
25 Mulatero P, Curnow KM, Aupetit-Faisant B, Foekling M, GomezSanchez C, Veglio F, Jeunemaitre X, Corvol P \& Pascoe L. Recombinant CYP11B genes encode enzymes that can catalyze conversion of 11-deoxycortisol to cortisol, 18-hydroxycortisol, and 18-oxocortisol. Journal of Clinical Endocrinology and Metabolism 199883 3996-4001.

26 Morello F, de Boer RA, Steffensen KR, Gnecchi M, Chisholm JW, Boomsma F, Anderson LM, Lawn RM, Gustafsson JK, LopezIlasaca M, Pratt RE \& Dzau VJ. Liver X receptors alpha and beta regulate renin expression in vivo. Journal of Clinical Investigation 2005115 1913-1922.

27 Han M, Liew CT, Zhang HW, Chao S, Zheng R, Yip KT, Song Z-Y, Li HM, Geng XP, Zhu LX, Lin J-J, Marshall KW \& Liew CC. Novel blood-based, five-gene biomarker set for the detection of colorectal cancer. Clinical Cancer Research 200814 455-460.

28 Lenzini L, Seccia TM, Aldighieri E, Belloni AS, Bernante P, Giuliani L, Nussdorfer GG, Pessina AC \& Rossi GP. Heterogeneity of aldosterone-producing adenomas revealed by a whole transcriptome analysis. Hypertension $2007 \mathbf{5 0} 1106-1113$.

29 Saner-Amigh K, Mayhew BA, Mantero F, Schiavi F, White PC, Rao CV \& Rainey WE. Elevated expression of luteinizing hormone receptor in aldosterone-producing adenomas. Journal of Clinical Endocrinology and Metabolism 200691 1136-1142.

Received 28 November 2008

Accepted 2 December 2008 